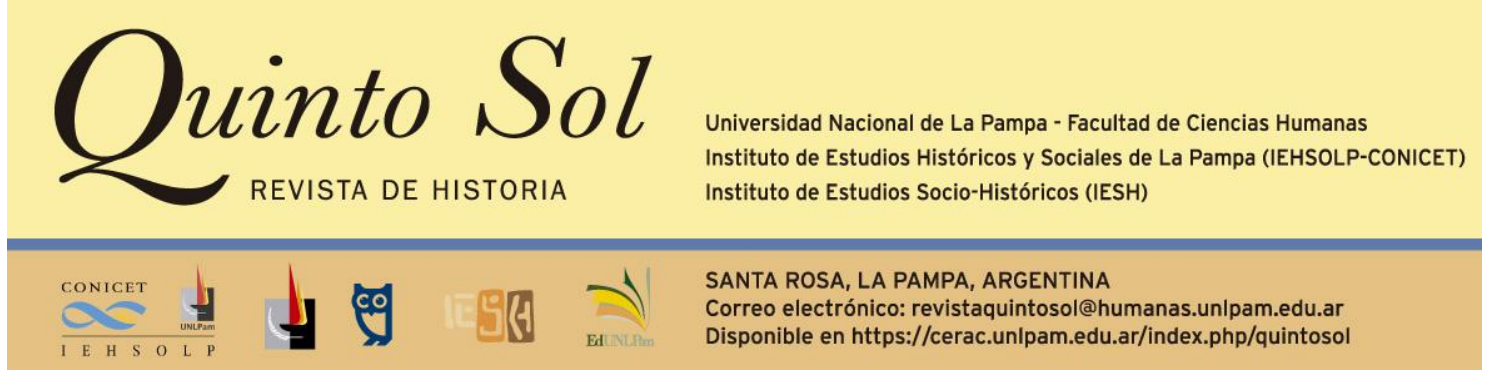

Quinto Sol, vol. 26, n¹, enero-abril 2022, ISSN 1851-2879, pp. 1-19

http://dx.doi.org/10.19137/qs.v26i1.5708

Esta obra se publica bajo licencia Creative Commons 4.0 Internacional. (Atribución-No Comercial-

Compartir Igual)

(c) (i) ()(2)

\title{
Las tribulaciones del sargento mayor. Conflictos de jurisdicción y relaciones fronterizas en el sur de Santiago del Estero a fines del siglo XVIII
}

\author{
The Tribulations of the Sargent Major. Conflicts of Jurisdiction \\ and Cross Border Relationships in the South of Santiago del \\ Estero at the end of the 18th Century
}

As tribulações do sargento-mor. Conflitos de jurisdição e relações fronteiriças no sul de Santiago del Estero no final do século XVIII

\section{Judith Farberman}

Consejo Nacional de Investigaciones Científicas y Técnicas

Universidad Nacional de Quilmes

Argentina

Correo electrónico: jfarberman@unq.edu.ar

\section{Resumen}

A partir de los expedientes de un juicio criminal contra el sargento mayor Gabriel Guillermo Espínola, miembro de una familia paradigmática del curato de Sumampa, este artículo se adentra en las relaciones sociales y en la historia política local, en dos dimensiones. La primera concierne al personaje y a su mundo doméstico en las sierras de Ambargasta. Acusado de robar ganado a través de sus protegidos y de

Palabras clave

frontera

colonia

conflictos de jurisdicción 
abusar de su autoridad por sus fueros, el proceso contra Espínola ilumina las tramas de parentesco, obediencia y dependencia, así como los conflictos de jurisdicción al momento de la creación de las intendencias del Tucumán y de la expansión de los agentes judiciales en la campaña. La segunda se refiere al Espínola comandante de fronteras en las cercanías del fuerte de Abipones y a su papel articulador con los grupos guaycurúes.

\section{Abstract}

Through the judicial adventures of Sergeant Major Gabriel Guillermo Espínola, a member of a paradigmatic family in the area, this article delves into social relationships and local political history in two dimensions. Accused of stealing livestock through his protégés and abusing his authority as a judge, the process against Espínola illuminates, on one hand, the kinship, obedience and dependency plots, as well as the conflicts of jurisdiction at the time of creation of the Tucumán "Intendencias" and expansion of the bailiffs in the countryside. On the other hand, it addresses Espínola's role as "Comandante de fronteras" near Concepción de Abipones and his close relationship with guaycurú Tribes in the Chaco region.

\section{Resumo}

A partir dos expedientes de um juízo criminal contra o sargento Gabriel Guillermo Espínola, membro de uma família paradigmática do curato de Sumampa, este artigo adentra-se nas suas relações sociais e na história política local, a partir de duas dimensões. A primeira, relaciona-se ao personagem e seu mundo doméstico nas Serras de Ambargasta, acusado de roubar gado através de seus protegidos e de abusar de sua autoridade local no momento da criação das intendências de Tucumán e da expansão dos agentes judiciais na campanha. A segunda, refere-se a Espíndola comandante de fronteiras nas proximidades do forte de Abipones e ao seu papel articulador com os grupos Guaycurúes.

\section{Keywords}

frontier

colonial period

conflicts of jurisdiction

\section{Palavras-chave} fronteira colônia conflitos de jurisdição 


\section{Las tribulaciones del sargento mayor. Conflictos de jurisdicción y relaciones fronterizas en el sur de Santiago del Estero, a fines del siglo XVIII}

\section{Introducción}

En noviembre de 1784, el sargento mayor Gabriel Guillermo Espínola (GGE) fue enviado a la ciudad de Córdoba para afrontar un juicio por abuso de autoridad. ${ }^{1}$ Aunque la causa terminó por resolverse a su favor, el jefe miliciano pasó más de dos años en prisión y le fueron embargados su hacienda y sus pocos esclavos. GGE era "natural y vecino del Paraje de las Horquetas", en Ambargasta, curato de Sumampa, al sur de la jurisdicción de Santiago del Estero, al igual que dos de sus presuntos cómplices -su hijo y un sirviente, con quienes compartió la prisión- y quienes declararon en su contra, sindicándolo como caudillo de ladrones y "tumultuarios" que vivían del ganado ajeno. Al menos cuatro miembros de la "pandilla" eran también agregados y subordinados militares de GGE, lo que volvía más inquietantes sus desafíos.

Con el concurso de otras fuentes, el expediente contra GGE puede acercarnos al peculiar mundo de la llamada "frontera de Chupilta", limítrofe con la jurisdicción de Córdoba y el curato santiagueño de Salavina, a fines de la colonia. Además de la posibilidad de reconstruir sumariamente la abigarrada trama de relaciones sociales de las que GGE participaba, la caída en desgracia del personaje permite formarse una semblanza de la política local, atravesada por conflictos de jurisdicción, desconfianzas y rivalidades frente a la popularidad y, quizás, capacidad de interlocución de ciertos jefes milicianos y con grupos indígenas fronterizos. De hecho, el proceso contra Espínola se inscribió en un período clave que tuvo entre sus hitos la creación de las intendencias de Salta y Córdoba del Tucumán -especialmente relevante en el sur de Santiago del Estero, confinante con el curato cordobés de Río Seco- y el incremento paralelo de los agentes judiciales en la campaña. ${ }^{2}$

Hemos optado por organizar este artículo en dos secciones que, grosso modo, coinciden con los tiempos del proceso judicial. Cada una de ellas nos trasladará a los

\footnotetext{
${ }^{1}$ Los expedientes de este largo proceso son: Cuaderno 1, Espínola Gabriel (sargento mayor), Abuso de autoridad, 1786, Criminal, Legajo 40, Expediente 40; Cuaderno 2, Autos criminales contra don Gabriel Espínola y su hijo don Gabriel, seguidos en Santiago del Estero, 1784, Criminal, Legajo 41, Expediente 9, y Cuaderno 3, Criminales contra Gabriel Espínola, 1784, Criminal, Legajo 45, Expediente 5. Todos ellos se encuentran en el Archivo Histórico de la Provincia de Córdoba, Córdoba, Argentina. En adelante, para simplificar la forma de citado en el texto, nos referiremos a los expedientes como Cuaderno 1, 2 y 3.

${ }^{2}$ Volveremos a este tema, sobre el que se acumula a esta altura una impresionante cantidad de trabajos. De momento y en razón de su especificidad, nos limitaremos a mencionar a Gabriela Tío Vallejo (1998); Gabriela Alessandroni y María Elizabeth Rustán (2001); Ana Inés Punta (2003); María Paula Polimene (2011); Romina Zamora (2011); Edgardo Dainotto (2012).
} 
Farberman, J. Las tribulaciones del sargento mayor. Conflictos de jurisdicción y relaciones fronterizas en el sur de Santiago del Estero, a fines del siglo XVIII

dos mundos diferentes, solo en apariencia disociados, por los que circulaba GGE. Nos concentraremos primero en el estanciero de La Horqueta, en la sierra de Ambargasta, y en su mundo doméstico para abordar posteriormente las andanzas del "comandante de las armas de esta frontera", cerca de la reducción de Concepción de Abipones, en las planicies al sudeste del curato. Los méritos militares de GGE, centrales en la argumentación de la defensa y a quienes está dedicada la segunda parte del trabajo, serían los que en 1786 determinarían finalmente la libertad del reo y de sus allegados.

\section{Un estanciero en el "Paraje de los Guillermos"}

Hacia 1720, la familia Espínola se encontraba ya instalada en la sierra de Ambargasta, una subregión en muchos sentidos diversa de la mesopotamia encerrada entre los ríos Dulce y Salado (ver Mapa). ${ }^{3}$ Presumimos que el capitán Guillermo Espínola, padre de GGE, fue el fundador de la estancia de La Horqueta, a la que quizás inaugurara al tiempo de su matrimonio con doña María Báez, con quien procrearon, por lo menos, seis hijos. Sin dudas, el capitán fue un personaje notable y con proyección regional: pocos hombres podían jactarse de tener entre los invitados para los esponsales de una hija al mismísimo gobernador de Tucumán, Matías de Angles. ${ }^{4}$ Así sucedió en 1738 en El Jume, sitio al que el párroco acudió con su altar portátil para entregar a Ana Espínola al porteño Juan Antonio Rodríguez. ${ }^{5}$ Por otra parte, el patrimonio territorial de la familia parece estrechamente ligado a las inversiones de aquel patriarca: además de La Horqueta y de la contigua estancia El Fuerte, Espínola agrandó sus posesiones comprando El Agua Blanca al heredero de la gigantesca merced de Ambargasta. ${ }^{6}$ Aunque sus sucesores luego dividieran su patrimonio, la historia de estas propiedades -significativamente reconocidas como parte integrante

\footnotetext{
${ }^{3}$ El curato de Sumampa era, en efecto, diverso de los del río Dulce (Rectoral, Tuama, Soncho y, en menor medida, Salavina) y de Matará y Guañagasta, sobre el Salado (Matará y Guañagasta), jaqueados ambos desde fines del siglo XVII por intermitentes ataques guaycurúes. Entre sus rasgos más notables, destacan los casi inexistentes repartos de encomienda, una estructura agraria dominada desde temprano por grandes estancias (en contraste con la agricultura de los bañados de los ríos Dulce y Salado), la relevancia de colonos y de beneficiarios de mercedes de origen cordobés y su configuración fronteriza, extensiva a los curatos cordobeses de Sobremonte y Río Seco, a partir del siglo XVIII. Débilmente poblado en 1778 (cuando contaba con 2144 habitantes y ocupaba el cuarto lugar en importancia de los siete distritos santiagueños), esa cifra se elevó a 3014 a fines del siglo. No obstante la escasa población y su monotonía productiva, algunas localidades del curato -Sumampa y Oratorio, por su importancia religiosa y comercial respectivamente- revestirían considerable importancia durante la era colonial y también en el siglo XIX. El traslado de la reducción jesuítica de Concepción de Abipones en 1751, por otra parte, generó un nuevo polo de atracción en el sur santiagueño, incluso con posterioridad a la expulsión cuando la élite santiagueña se disputó las tierras, conocidas por sus óptimas pasturas, y formó allí grandes estancias. Los censos referidos se encuentran en Antonio Larrouy (1927) y en dos transcripciones (Togo, Garay y Bonetti, 2009; Siegrist, 2011). Sobre la historia de Sumampa, véanse Bravo y Taboada (1944), Ledesma (1957) y Gramajo y Martínez Moreno (2005). Un primer análisis de la estructura demográfica y agraria del curato colonial puede consultarse en Farberman (2019).

${ }^{4}$ No obstante, contamos hasta ahora con muy pocas referencias biográficas. Es posible, como anticipamos, que su linaje fuera cordobés y que haya desarrollado parte de su carrera miliciana en la provincia vecina.

5 "Sumampa, Quebrachos, Santiago del Estero, Argentina Registros," imágenes, FamilySearch (https://www.familysearch.org/ark:/61903/3:1:9396-CW9F-C, 5 de noviembre de 2021), imagen 145 de 136; Diócesis De Añatuya.

${ }^{6}$ Romualdo Vazquez y compartes. Mensuras de Quebrachos. Mensura, deslinde y amojonamiento de Horquetas. 1894, Legajo 1. Antiguo Departamento Sumampa, actual Quebrachos. Archivo Histórico de la Provincia de Santiago del Estero (AHSDE), Santiago del Estero, Argentina.
} 
Farberman, J. Las tribulaciones del sargento mayor. Conflictos de jurisdicción y relaciones fronterizas en el sur de Santiago del Estero, a fines del siglo XVIII

del "Paraje de los Guillermos"- está constelada de numerosas compras intrafamiliares, préstamos, explotaciones conjuntas y traslados de parientes, lo que sugiere una gestión común de las actividades agrarias -visible también en las declaraciones contenidas en el expediente- destinada a perdurar.

Mapa: sitios significativos del curato de Sumampa en el siglo XVIII

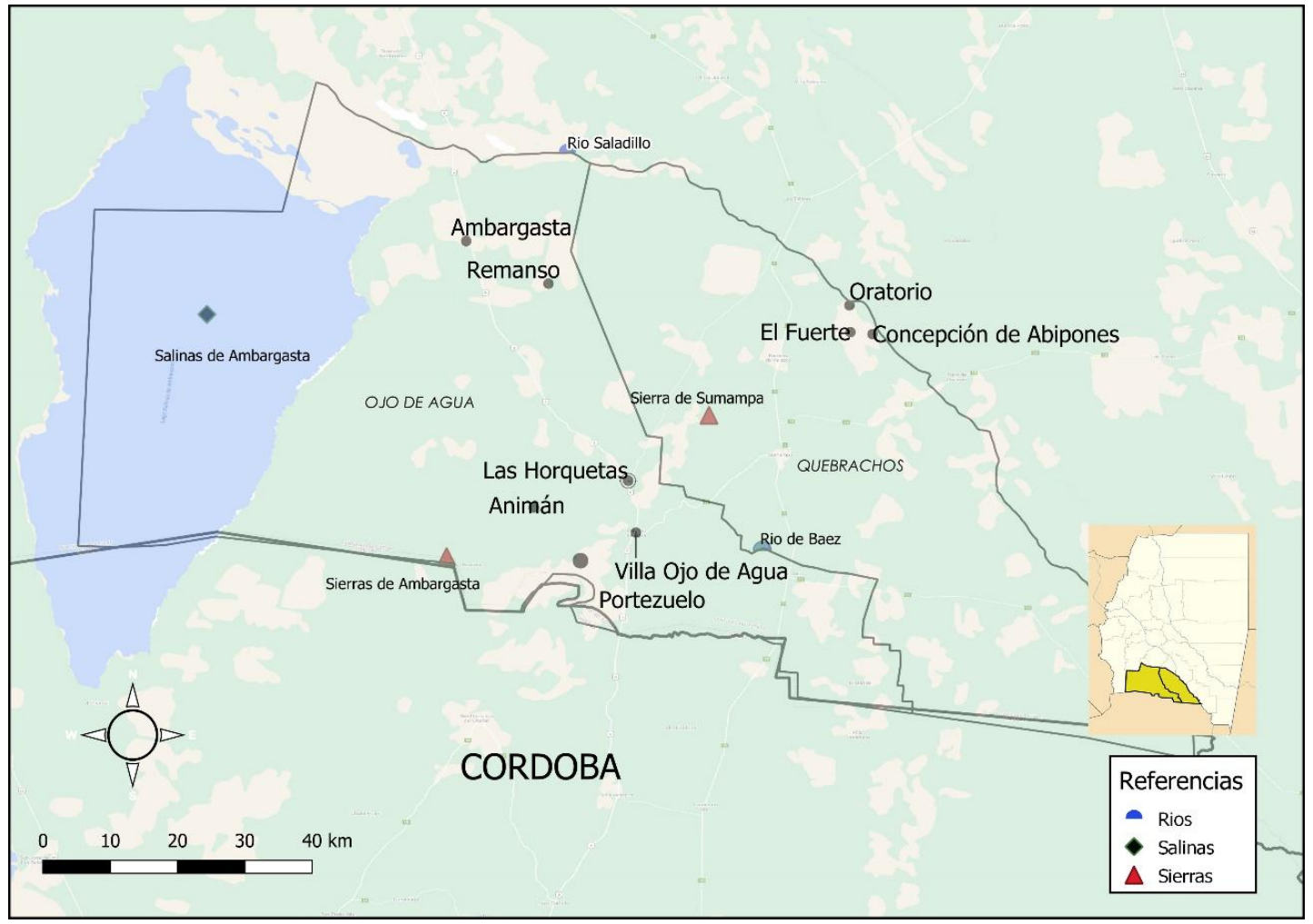

Fuente: Archivo personal de la autora. Elaboración: Muriel Mariño Canales.

Según nuestros cálculos, GGE nació en 1731 y superó la barrera de los 90 años. ${ }^{7}$ Tenía 20 cuando desposó a Juana Crespín, hija de los herederos de la merced de Tanache, para entonces bastante empobrecidos. Diversas fuentes nos han permitido rastrear a cuatro de los hijos de la pareja y a tres de sus nietos: varios de ellos permanecerían en el "Paraje de los Guillermos", o en las aguadas aledañas a Ambargasta hasta bien entrado el siglo XIX. También alguna gente de su servicio, como en breve veremos, heredó el apellido del sargento mayor, hasta hoy muy difundido en la zona.

GGE fue, indudablemente, un personaje notable dentro de la élite local, aunque menos rico y prestigioso que su padre. ${ }^{8}$ Según confesó en 1784 , la estancia de La Horqueta -donde vivía con la familia de su hijo Gabriel y todos sus agregados- le

\footnotetext{
7 Carranza Elmira. Mensura, deslinde y amojonamiento Pampa Grande, 1909. Mensuras de Quebrachos, Legajo 1, folio 18. AHSDE. En el extracto de títulos de la estancia de Pampa Grande figura un documento de 1816 en el que GGE es convocado como informante para colaborar en el establecimiento de los límites de la estancia. Se sostenía la utilidad de "la declaración de los más ancianos del lugar como lo son los supradichos y en particular el sargento mayor Espínola que se dice tiene mas de cien años."

${ }^{8}$ Por ejemplo, procuró, sin éxito, acrecentar el patrimonio territorial de la familia. Sabemos de su fallido intento de compra de El Jume a su vecino Miguel Mansilla. Mansilla María y otro a Córdoba Mariano por venta de unas tierras, 1811. Tribunales, Legajo 16, Expediente 29. AHSDE.
} 
pertenecía a su difunto hermano Josep, mientras que a él le había tocado El Fuerte, "cuios instrumentos sabe que el finado padre de este declarante se los entregó al maestro D. Juan Jph de Ávila, asimismo difunto". ${ }^{9}$ Preguntado por sus bienes, además de la casa de su vivienda y de los corrales en tierras de Josep, GGE enunció una discreta cantidad de ganado, que coincidía aproximadamente con la que, tras una complicada averiguación, las autoridades lograron embargarle. ${ }^{10}$ Por otra parte, poseía en La Horqueta tres chacras de trigo y de maíz -una a medias con la suegra de su hijo Gabriel- y una mulata esclava, María, con sus tres "mulatillos". ${ }^{11}$

Los esclavos eran una rareza en las campañas de Santiago, por lo que resulta notable que el no tan rico GGE tuviera cuatro, y Gabriel, uno más. ${ }^{12}$ Sin embargo, el dato más llamativo -y aludido por todos los declarantes sin excepción- era que María fuera la esposa de Pedro Martínez, primo hermano de Juana Crespín y compañero de desgracia de los Espínola. Aunque estos lazos no impidieron el embargo, la ambigüedad de la situación de Martínez recorre todo el expediente y vuelve más atractivo al personaje.

Además de los esclavos, seguían a Espínola un número indeterminado de parientes -de sangre y políticos- y de agregados que "se albergaban de su respeto" y que, a la vez que contribuían con los trabajos agrarios, conformaban en varios casos su tropa miliciana. Siguiendo a los vecinos denunciantes, aquéllos secundaban las actividades delictivas de GGE: con ellos habría repartido el sargento mayor los botines conseguidos (carne, ropa, armas) y en su compañía desafiaba "tumultuariamente" a las autoridades judiciales que pretendían corregir sus desmanes. Eran dos caras de una misma moneda, dos dimensiones de un liderazgo probablemente reforzado por el grado miliciano -que exhibían también Gabriel Espínola- y el cuñado Juanico Crespín y, en su tiempo, el difunto Josep Espínola.

Algunas pistas adicionales sobre el mundo inmediato de los Espínola surgen de las confesiones de los reos -GGE, Gabriel Espínola y Pedro Martínez-, y conviene empezar por ellas. Gabriel contaba 25 años en 1784 y, según don Marcos de Posadas, antiguo juez pedáneo y adversario de GGE, era un "muchacho jugador y de relajadas costumbres" al que su padre "sin la más leve facultad" había designado capitán de una compañía. Junto con su esposa, Catalina Sánchez, Gabriel integraba la casa de La Horqueta, aunque su patrimonio personal se redujera a "un mulatillo de doce años llamado Pedro Antonio habido... de heredad por parte materna, 6 caballos zebrunos

\footnotetext{
${ }^{9}$ Documentación posterior permite inferir que los hijos de GGE terminaron heredando El Agua Blanca y que un nieto de aquel -Gregorio Espínola- volvió a reunir en el siglo XIX el antiguo patrimonio territorial del primer Espínola que conocemos. Romualdo Vázquez y compartes. Mensura, deslinde y amojonamiento de Horquetas, 1894. Mensuras de Quebrachos, Legajo 1, folio 8.

${ }^{10}$ El patrimonio declarado por GGE incluía una manada de ocho caballos bayos con madrina y cencerro, otra de rosillos de cinco con su madrina y cencerro, dos manadas de yeguas "qe se componen de pocas", una majada de cuarenta ovejas y cabras, catorce vacas lecheras y un novillo. Declaró, además, haber empeñado ocho caballos y decía tener otros veinte de un vecino, tres sin marca y ocho pertenecientes al rey (Cuaderno 2, folio 36 vta.).

${ }^{11}$ Las justicias no creyeron en la declaración patrimonial de GGE. Temían por el reparto y el ocultamiento de la hacienda entre parientes y vecinos y los posibles envíos a la zona de la reducción. Especialmente, desconfiaban sobre el destino de los esclavos, el capital más valioso, que terminaron incautando en la casa de la suegra de Gabriel Espínola. Según Juanico Crespín, cuñado de CGE, había tenido que negarse al pedido de su hermana de esconderlos "porque era un pobre y qe podía venir la justicia por ellos" (Cuaderno 2, foja 35).

12 El censo de 1794 (Siegrist, 2011) consigna 43 esclavos para todo el curato, menos del $2 \%$ de la población.
} 
con madrina y cencerro y una manada de yeguas de quince entre chicas y grandes" (Cuaderno 1, f. 40). Asimismo, el joven capitán se servía de su tío segundo y peón, el ya mencionado Pedro Martínez, mejor conocido por su alias, Pillo Macana.

Intermediario perfecto entre los mundos que GGE intersectaba, Pillo Macana que se presentó como "criollo del paraje de Oveja Llaco... regularmnte tenido por mestizo"- reconocía en realidad alternativamente a sus amos en el padre y en el hijo, y a ambos denunció con aspereza. ${ }^{13}$ En su confesión, recordó su doble perfil de pariente y servidor de la casa, aludió a los maltratos físicos que se le habían infligido (como haber sido "castigado colgado") y, quizás más importante, a su sistemática exclusión en los repartos.

Así lo ejemplifica una anécdota repetida por varios declarantes, que muestra a las claras cómo el lazo de servidumbre le ganaba al del parentesco con Juana Crespín. Al parecer, el joven Gabriel había engañado a un trajinante vallisto disfrazando a Pillo Macana con su "ropa decente" y enjaezando debidamente su caballo. Especulaba con que, vestido de español, el sirviente podría robarse la carga de algodón y pasas que trasladaba el mercader sin despertar sospechas. ${ }^{14}$ En otra ocasión, por orden de los Espínola y con la complicidad de unas agregadas suyas, Pillo Macana había asaltado a un caminante. Como era habitual, del reparto de la ropa de la víctima solo se habían beneficiado los primos Gabriel y Cesario Espínola y el tío Juan Crespín, dejándolo otra vez con las manos vacías.

¿Qué otros personajes integraban el clan de los Espínola, según los confesantes? Acabamos de mencionar a Cesario, hermano de Gabriel, y a Juan Crespín. También los sobrinos de GGE, Marco Antonio, Pedro Mariano y Alejandro posiblemente, hijos del difunto Josep- fueron mentados como socios en las fechorías que amenazaban la seguridad de vecinos y transeúntes. Según Pillo Macana, aquellos muchachos eran salteadores y andaban "encarados con pañuelos pa. asustar a los... pasajeros" y que "del hecho hacían chanza y risa... contando la defensa que hicieron con las armas" (Cuaderno 2, f. 52 vta).

La familia política de Gabriel Espínola -su suegra, Juana Moriñigo, y los Sánchez- se encontraba asimismo involucrada en las denuncias de la sumaria. Sin embargo, vale la pena demorarnos algo más con los Sánchez, otro ejemplo de superposición entre vínculos verticales y horizontales, entre parentescos y relaciones milicianas. Como ya dijimos, Gabriel Espínola estaba casado con Catalina Sánchez, quien, de acuerdo con nuestras pesquisas genealógicas, era hija de Asencio y de Juana Moriñigo. ${ }^{15}$ Lo interesante es que Asencio Sánchez había sido un histórico agregado del capitán Guillermo Espínola en El Agua Blanca, y que su hijo Josep lo había "heredado" junto con la estancia. En 1766, Josep Espínola había conseguido "lanzar" a

\footnotetext{
${ }^{13}$ Por ejemplo, en una de sus declaraciones confirmó que era cierto que "se mantenían robando así su amo como agregados continuamente bueyes, vacas, novillos y terneros" y agregó una prolija relación de las víctimas de los robos -todos vecinos, varios testigos de la sumaria- y del número de animales sustraídos para vender y para "el gasto de la casa" (Cuaderno 2, folio 50).

${ }^{14}$ Declaración de Juan Antonio de la Cruz "dijo haber oído decir que dho Martínez se vistió con ropa decente y fue a petardear a un vallisto" (Cuaderno 2, folio 52). En palabras de Pillo Macana, Gabriel le proponía que "volviendo... a tu traje y desnudez, no ha de saber con quién trató y que tan solamente trató un peso de pasas por lo acabado del algodón y qe dicho peso lo pagó con un potro."

${ }^{15}$ Casamiento de Asencio y Juana: "Sumampa, Quebrachos, Santiago del Estero, Argentina Registros," imágenes, FamilySearch (https://www.familysearch.org/ark:/61903/3:1:9396-CW98-6), imagen 160 de 263; Diócesis De Añatuya.
} 
Asencio Sánchez de su terreno: ¿restañaba acaso antiguas heridas el matrimonio entre Gabriel y Catalina? ${ }^{16}$ Como fuera, otros dos Sánchez, de la misma familia, surgen en las declaraciones de la sumaria, siempre como dependientes: Gildo, agregado de GGE, y Jacinto, cabo de escuadra de la compañía de Gabriel Espínola. ${ }^{17}$

Por supuesto que el universo de los agregados de los Espínola resulta más nebuloso que el de los parientes. Varias declaraciones se refieren a Casimiro Cortés y a sus hermanos Juan Josep, Hipólito y Juan Asencio, generalmente identificados como mulatos. Casimiro había "vivido en fe de casado muchos años con Josefa Romano, lo que denunció al cura de este beneficio su mala vida y los casó" (Cuaderno 1, f. 37) y, según Pillo Macana, era quien había escondido parte del ganado de su amo en la reducción para salvarlo del embargo. También otro agregado mulato, Alejo Espínola, era objeto de numerosas acusaciones, y el mismo GGE reconoció haberlo entregado alguna vez a la justicia por "acumularle algunos" (delitos), que no pudieron justificársele. En todo caso, "los Corteses", Alejo y otros individuos formaban parte de ese colectivo sin bordes precisos al que, genéricamente, los testigos calificaban de "agregados, mulatos salteadores y esclavos fugitivos", todos ellos "cobijados en el respeto" del sargento mayor. No solo eran temibles por sus robos: también por su complicidad con célebres criminales -uno de los declarantes mencionó a los hermanos Pablo y Silverio Leguizamo $-y$, fundamentalmente, por hallarse siempre "fuertemente armados". ${ }^{18}$

Y quizás fuera esta la arista más inquietante de nuestro hombre: la notable popularidad que cosechaba entre los integrantes de su séquito y más allá. Vimos que este favor tenía, al menos en parte, bases materiales -ya se habló de la redistribución del producto de los robos y de la participación en diversos negocios ganaderos-. Sin embargo, no se trataba del único atractivo. Entendemos que lo que sus contrarios llamaron "abuso de autoridad" pudo ser leído en clave política por los menesterosos seguidores de GGE. En efecto, como surgió ya de nuestro relato, un eje central en las denuncias contenidas en la sumaria apuntaba a la tendencia de nuestro hombre y de los suyos a "atumultuarse". Y, no casualmente, los blancos de los tumultos solían ser agentes judiciales nombrados por el cabildo (además de vecinos con quienes ya existía un historial de conflictos). Analicemos estas cuestiones a través de cuatro incidentes concretos que recogen diversos testigos y que también pueden leerse como emergentes de la "reforma judicial" borbónica y sus repercusiones locales. ${ }^{19}$

\footnotetext{
${ }^{16}$ Espínola José contra Sánchez Asencio sobre despojo, 1766. Tribunales, Legajo 19, Expediente 107.

${ }^{17}$ Gabriel Espínola evitó que Jacinto Sánchez, cabo de escuadra de su compañía, se presentara al juzgado. Al parecer, le aconsejó que siguiera a su padre "en solo qn tendría refugio" (Cuaderno 1, folio 5). Aunque las justicias lo prendieron, hizo fuga inmediatamente.

18 Los hermanos Leguizamo fueron juzgados en 1793. Leguizamo Pablo, sobre calumnias e injurias, 1793. Tribunales, Legajo 9, Expediente 73. Basándose en el expediente criminal, escribió Bernardo Canal Feijoo, en 1937, su obra de teatro Pasión y muerte de Silverio Leguizamón. Volveremos sobre este jugoso caso en las conclusiones.

${ }^{19}$ Desde 1783, Córdoba fue ascendida a capital de intendencia y, como ha señalado Edgardo Dainotto (2012), el pragmático marqués de Sobremonte le aportó a la reforma de la justicia características singulares. Mientras que, por ejemplo, en San Miguel de Tucumán, las reformas borbónicas terminaron por reforzar la autoridad del cabildo en materia de administración de justicia (Tío Vallejo, 1998), en Córdoba, Sobremonte consiguió la colaboración del cuerpo capitular. Resignificó las funciones y el marco normativo en que actuaban los jueces pedáneos y logró someterlos a su autoridad (reservándose, por ejemplo, el derecho a dictar sentencias, como ocurrió en el caso de Espínola).
} 
El primer episodio consistió en un enfrentamiento entre GGE y el juez pedáneo y capitán de milicias don Pedro de Acuña y Negrete por el traslado de un preso (según GGE, un desertor). Al parecer, Acuña había reprendido al sargento mayor por llevar atado a un soldado español, y este había respondido embistiéndolo con su cuchillo. Además de la significativa cuestión acerca de la calidad del prisionero -parte de la mala fama de GGE pasaba por rodearse y favorecer a gente de "bajo nacimiento", la otra cara del castigo inadecuado de los españoles-, no era un tema menor que, según sus detractores, nuestro hombre tuviera una cárcel en su estancia y que cobrara por los carcelajes.

Del segundo incidente, que involucró al sargento mayor y juez pedáneo don Santiago de Herrera -de quien GGE era entonces ayudante-, el proceso recoge dos versiones distintas, mientras que una tercera quedó registrada en las actas capitulares en $1773 .^{20}$ Según los hijos de Herrera, que se sumaron como querellantes a la causa y luego se arrepintieron, todo había comenzado cuando se le exigió a GGE que entregara a la justicia a una esclava huida y refugiada en Las Horquetas. Ofendido por la orden, GGE y su hermano Josep, acompañados del habitual cortejo de "agregados y mulatos salteadores y esclavos fugitivos", habían atropellado a Herrera -hiriéndolo de muerte- y a su guardia. En la versión de GGE -ascendido a sargento mayor luego del incidentetodo se había desmadrado en el intento de rescatar de la cárcel a su "hermanito" (SIC) Antonio. Le había ofrecido a Herrera pagar por la soltura -entendía que la prisión era por deudas-, se había trenzado con unos de los guardias, y, por accidente, había segado la vida del juez pedáneo que intentaba mediar en la pelea. ${ }^{21}$

El tercer episodio nos muestra a GGE enfrentado con el entonces alcalde de Santa Hermandad Josep de Frías. Aquella vez "le acometió dho sarg.to mayor armado de todas armas y con un par de pistolas y con lanzas, y al rigor de sus armas le quitaron unos animales qe dho alcalde tenía embargados":22 Nicolás Fernández Saavedra, acompañante de Frías en aquellos hechos, los relató con gran dramatismo: llegados a Ojo de Agua, "vieron venir una comitiva de gente, como cosa de treinta o cuarenta hombres armados, formados en dos columnas y en medio de ellos el sargento mayor." Según el testigo, GGE había obligado a Frías a apearse ("¿qué es esto que se me cerca mi persona?", había exclamado el alcalde frente a tamaña insolencia), espetándole que sería él quien se llevaría los animales, como de hecho ocurrió (Cuaderno 1, f. 9).

Por último, el cuarto conflicto de magnitud se había producido en la festividad de Santa Ana, cuando GGE cruzó algunas provocaciones con el capitán de milicias don

\footnotetext{
${ }^{20}$ En las actas del cabildo se denuncia que el alcalde de hermandad don Josep Varela había omitido entregar a los reos para quedarse con "nueve bueyes y otras cosas" que les pertenecían. Tuvo que intervenir el alcalde de segundo voto, que encerró a los Espínola en la cárcel capitular hasta que fueron absueltos por considerarse que Varela había violado y atropellado "los fueros jurídicos y que en mutua correspondencia... se debe observar entre los jueces". Archivo Histórico de Santiago del Estero, 2013, Actas III, pp. 209-213.

${ }^{21}$ No hay dudas de que GGE había tenido que ver en la muerte del sargento mayor Herrera; de hecho, había recibido un indulto en su momento. La hija de Herrera, Sabina, se arrepintió de colaborar con los "enemigos capitales" de GGE y le envió una carta a la cárcel en la que expresó sentir en el alma que aquellos quisieran "acosarlo por el fallecimiento de mi amado padre". En apariencia, los hermanos Herrera desistieron de la querella contra GGE cuando se les informó que debían apersonarse en Córdoba, un viaje que no podían costear (Cuaderno 2, folio 96).

${ }^{22}$ Corresponde a la declaración del capitán don Juan Negrete de Acuña (Cuaderno 1, folio 3).
} 
Farberman, J. Las tribulaciones del sargento mayor. Conflictos de jurisdicción y relaciones fronterizas en el sur de Santiago del Estero, a fines del siglo XVIII

Josef Antonio Rojas. ${ }^{23}$ Según el testigo Nicolás Fernández Saavedra, nuestro hombre había amenazado a Rojas con un trabuco y este:

estimulado... de ver tanto insulto... le dijo si un señor sarg.to maior se vale de los suios y sus armas, me veré precisado a traer los míos armados y (vino) el aiudante de dho Espinola con la espada desnuda en mano y uno de los soldados de dho capn con el cuchillo en las manos y pr consiguiente dho Rojas con sus armas se aquietó. (Cuaderno 1, f. 8)

Finalmente, el párroco Espinosa, "con su prudencia y carácter", había conseguido detener "la pendencia que hubo de suceder pr razón de estar ya apandilladas ambas partes". ${ }^{24}$

Notemos que tres de los cuatro incidentes apuntan a conflictos con agentes de la justicia capitular -dos de ellos, con grado miliciano-, mientras que el último confrontaba a dos oficiales de distinto rango. Cabe recordar también que el proceso mismo contra GGE había sido iniciado por el alcalde de Santa Hermandad en funciones, don Domingo de Santillán, y que los testigos de la sumaria por él convocados, "capitales enemigos" del reo, habían sido todos ellos pedáneos o alcaldes de Santa Hermandad que habían tenido algún papel en los embargos y/o en las averiguaciones. ${ }^{25}$ La escalada del conflicto no era, por lo tanto, casual y trascendía al personaje. Como han subrayado los recientes trabajos sobre historia de la justicia, estos años de vigoroso reformismo, coincidentes con los de creación de las intendencias, lo fueron también de multiplicación de los agentes judiciales en la campaña y de un intento de separar funciones y prerrogativas entre instituciones y autoridades (Tío Vallejo, 1998; Polimene, 2011; Dainotto, 2012; Barriera, 2018, entre otros). Por lo tanto, existía también un trasfondo jurisdiccional en las disputas que algunos de los testigos contrarios y favorables a GGE- reconocieron abiertamente. ${ }^{26}$

En este sentido, según don Marcos de Posada, juez comisionado:

Todos los alcaldes de Santa Hermandad salen disparando destos partidos por el temor y miedo qe le tienen porque este haciéndose juez facultativo y sin principio alguno hace pagar dependencias, aprehende, castiga y deposita mujeres teniendo su casa por cárcel, estafando a los reos y cobrando los carcelajes, y con tan irregular modo de proceder

\footnotetext{
${ }^{23}$ En la sumaria se recogen numerosos relatos de reyertas de GGE en fiestas religiosas. Se mencionan por lo menos cuatro, todas en la zona: Santa Ana, Nuestra Señora de la Consolación de Sumampa, Nuestra Señora del Rosario (Totorilla) y una más en el Oratorio.

${ }^{24}$ La cursiva es nuestra.

${ }^{25}$ Había sido el alcalde de Hermandad Domingo de Santillán quien levantara la sumaria contra GGE y recogiera las declaraciones en su estancia de Cachi de Manchín. Vista la gravedad del caso, Santillán había solicitado al gobernador intendente de Salta, Andrés Mestre, que siguiera la causa. Por orden de Mestre, GGE fue arrestado en octubre de 1784 en casa de don Antonio García de Villegas, también capitular. La causa -y sus reos- pasarían a Córdoba en noviembre de 1784. Según Mestre, lo ameritaba la distancia entre Salta y Santiago del Estero, así como la escasa seguridad de la cárcel santiagueña y la "imposibilidad de poder ser remitidos por menor castigo al Fuerte" (Cuaderno 2, folio 46).

${ }^{26}$ Los conflictos jurisdiccionales eran consecuencia de la fuente de autoridad que investía a las justicias y de las crecientes facultades -que incluían tareas de policía y gobierno- asignadas a los jueces pedáneos (Dainotto, 2012, p. 170). El cabildo de Santiago del Estero comenzó a designar jueces pedáneos a partir de 1770 para auxiliar a los alcaldes de Hermandad. Aunque era corriente que estas nominaciones recayeran sobre jefes milicianos, como se ve en dos de los ejemplos expuestos, en los incidentes relatados, el conflicto residiría en la desautorización del sargento mayor, que cumplía de hecho con funciones judiciales, por parte de los jueces nombrados por el cabildo y ahora dotados de mayor poder y control territorial.
} 
usurpando la jurisdicción y justicia a los sres jueces en términos de que al más leve movimiento se hallan tumultuados y alzados los soldados de la compañía de Gabriel Espínola. (Cuaderno 1, f. 18)

Viceversa, el varias veces alcalde de primero y segundo voto don Antonio García de Villegas, sostenía que Santillán y Frías habían prendido a su amigo GGE por ser "sus rivales declarados por competencias de jurisdicción qe en sus varas de la hermandad con dho Espínola como cabo militar porque defendía su fuero" (Cuaderno 3, f. 10).

Por lo tanto, los enemigos de GGE habían encontrado el momento más oportuno para sacar a relucir disputas personales, quizás acumuladas desde antiguo. Disputas relativas al honor, al respeto de las jerarquías (¿qué clase de sargento mayor era este que humillaba y encarcelaba a los españoles mientras recogía esclavos huidos en su casa?) y a las competencias entre agentes judiciales y jefes milicianos, escenificadas en una contienda en la que intervenía gente armada (¿solo la compañía de Gabriel Espínola?) y "apandillada". ${ }^{27}$ Como ha sostenido Raúl Fradkin (2009), las jefaturas milicianas podían contribuir a sostener la autoridad de los estancieros, como también lo era Espínola. Pero ¿hasta qué punto el sargento mayor era, como sostuvo una vez Juan Carlos Garavaglia (1984), un jefe miliciano de "vara y mostrador" ${ }^{28}$ La argumentación de la defensa, en buena medida, giraría sobre este particular.

\section{Un "comandante de las armas de esta frontera"}

Hemos visto hasta aquí que tanto la mayor parte de los testigos que se dijeron víctimas de robos de ganado y de abusos de autoridad del sargento mayor como los integrantes de su plebeyo séquito provenían de la sierra de Ambargasta. Sin embargo, ya anticipamos que GGE -y quizás también su padre, el capitán Guillermo Espínola- se movían entre La Horqueta y Concepción de Abipones, punto fundamental de la llamada "frontera de Chupilta". ${ }^{29}$

Como era esperable, el alegato de la defensa procuró alejar a GGE de sus dudosos socios de La Horqueta para concentrarse en los servicios al rey del comandante de fronteras, que, a la postre, determinaron su soltura. Según el defensor, GGE había tenido un desempeño protagónico en dos resonantes expediciones al Chaco: la organizada por el gobernador don Gerónimo de Matorras en 1774 y la de la

\footnotetext{
27 Edgardo Dainotto (2012) presenta ejemplos similares al antes relatado de contiendas de jurisdicción entre comandantes militares y jueces. Visto desde la capital de intendencia, estas "se transformaron en una ocasión para que el Intendente, la máxima autoridad, vértice de la pirámide y fuente de legitimidades derivadas pudiera ejercer un control sobre sus propios delegados y en última instancia, aplicara personalmente penas y perdones en función de intereses políticos" (p. 193). Fue, de hecho, lo que ocurrió con Espínola (cuyo caso el autor menciona y describe brevemente), a quien Sobremonte terminó absolviendo.

$28 \mathrm{Si}$ es que Juan Carlos Garavaglia quiso decir, como interpreto, un jefe miliciano que ejercía las prerrogativas judiciales de su fuero, pero evadía los servicios propiamente militares.

${ }^{29}$ Sobre esta porción de la frontera indígena que Santiago del Estero compartía con Córdoba, existen trabajos específicos de gran interés como los de Ana Inés Punta (2001) y Daniela Sosnowski (2020). Las autoras mencionadas se diferencian por el peso que le otorgan a la eficacia de la política reduccional en términos de seguridad fronteriza, que Sosnowski relativiza, como también lo interpretaron Farberman y Ratto (2014) en relación con la frontera santafesina-santiagueña sobre el río Salado. Asimismo, corresponde mencionar los trabajos de Carina Lucaioli referidos a los abipones y los orígenes de Concepción (Lucaioli, 2011, 2014).
} 
búsqueda de la "mina de Fierro" de 1783, comandada por Miguel Rubín de Celis. ${ }^{30}$ También le adjudicaba la desarticulación de una rebelión abipona durante la visita del gobernador Matorras a la reducción (en 1770) e indeterminadas acciones que habían habilitado el retorno del tráfico comercial al Camino de los Porongos, antes "infestado por los salvajes". ${ }^{31}$ Por último, se les preguntaba a los testigos por la leva local organizada por GGE para combatir las rebeliones tupacamaristas, por su permanente dedicación a "perseguir ladrones, desterrar y ahuyentar bandidos y salteadores asegurando los caminos y custodiando a los superiores" y por la enemistad que los testigos convocados por don Domingo de Santillán -"hombres de perversas costumbres"- profesaban hacia GGE (Cuaderno 3, f. 2).

Lo más notable de este nuevo conjunto de declaraciones es que, aunque proporcionadas por la defensa, no favorecían demasiado al reo. Solo lo ensalzaron los testigos que no tenían trato cotidiano con GGE, mientras que sus vecinos y compañeros de armas de Sumampa, cuando no pretextaron ignorancia sobre las preguntas, desmintieron o minimizaron las proezas que se los llamaba a confirmar. Con todo, estas voces disonantes -y una breve sumaria posterior levantada una década más tarde en Santiago del Estero- nos permiten avanzar, aunque de manera muy especulativa, sobre una cuestión crucial, cual es la relación de GGE con los abipones reducidos y otros grupos chaqueños. ${ }^{32}$

Concentrémonos, en primer lugar, en quienes atribuyeron ribetes épicos a las acciones de GGE, dos personajes de prestigio y varias veces citados en las declaraciones: don Miguel Rubín de Celis -cabeza de la expedición a la "mina de fierro"- y su superior, el coronel don Antonio del Castillo.

En rigor, Rubín de Celis se limitó a enviar una certificación de servicios en la que justificaba haber designado a GGE como ayudante mayor "por su reconocimiento en el país enemigo". Le atribuía, además, haber vuelto del Chaco "dicho Espínola con tres caciques qe mandaban un considerable número de indios a rendir su obediencia" (Cuaderno 2, f. 77). ${ }^{33}$ Por su parte, Antonio del Castillo fue todavía más enfático: estimó en cuatrocientos el "considerable número de indios" referido vagamente en la certificación y los describió como amenazantes y feroces, "con armas y apariencias de impedir la marcha". "De no haberlo socorrido a tiempo con su compañía, habría muerto el gobernador", argumentó Castillo, y así elevó la protección ofrecida a Matorras en Concepción de Abipones a gesta casi personal de GGE. Por fin, en lo que tocaba a la expedición de 1774, la respuesta de este testigo se ajustaba a la pregunta según la cual GGE había sido "el único en ofrecerse" y, munido de un "curioso diario", se había internado en el Chaco con solamente otros cuatro guerreros.

No nos dejemos deslumbrar por estos hechos, que los declarantes más próximos a GGE pronto desmentirían. Sin embargo, incluso quienes le bajaron el precio,

\footnotetext{
30 Sobre la campaña de 1774 y el tratado con Payquín puede consultarse Florencia Nesis (2008) y María Laura Cutrera (2019); para la expedición al Fierro, además del artículo que el mismo Rubín de Celis escribió en 1788 para una revista científica de la época, ver José Sellés Martínez (2020).

${ }^{31}$ Para esta visita de Matorras a Concepción de Abipones, consultar José Luis Togo et al. (2008).

32 De los abipones reducidos, en rigor, debían quedar ya muy pocos. La reducción había comenzado a declinar diez años antes de la expulsión de los jesuitas, para derrumbarse después como estructura de contención, evangelización y defensa. También se deshizo a fines del siglo XVIII el abundante patrimonio ganadero reunido por la orden (Farberman y Ratto, 2014).

33 Esta información, magnificada, se incorporaría posteriormente como pregunta al interrogatorio de la defensa, que directamente le adjudicaba a Espínola "el acierto de la expedición."
} 
no dejaron de reconocerle al sargento mayor una experticia que nos permite pensar en su "segunda vida" de jefe miliciano en la frontera de Chupilta. Así surge del testimonio de su prominente amigo Antonio García Villegas, que conocía a nuestro personaje desde que era un joven alférez. Había sido él quien, en su calidad de presidente de Temporalidades, nombrara al sargento mayor juez conservador de la reducción de abipones: a sus méritos le atribuía el orden mantenido allí "a su costa y mención", orden que el prolongado encarcelamiento había quebrado. ${ }^{34}$ Sin embargo, los elogios que aquí más nos interesan apuntaban a las razones de Rubín de Celis para solicitar la compañía de GGE en la expedición del fierro:

se lo nombró a Espínola pr único de su confianza... por su baquía, versado en los tratos $y$ en la lengua de indios, qe encontrándose con estos en el paraje del fierro libertó al jefe y su tercio de aquellos infieles por cuio motivo dho comandante [Miguel Rubín de Celis] le dio las gracias. (Cuaderno 3, f. 10 vta.) ${ }^{35}$

Baquía, experiencia en tratos con los indios y conocimiento de la lengua: he aquí el verdadero capital de un GGE en su mejor versión, el capital que hacía de los oficiales fronterizos seres anfibios, bisagras entre dos mundos. Aunque el protagonismo del sargento mayor en el episodio parezca exagerado, sus responsabilidades en la frontera, cierto conocimiento del territorio y su trato frecuente con la población fronteriza eran elementos que, razonablemente, aportaban a una baquía.

En contraste, las declaraciones de los testigos sumampeños trasuntan una visible molestia por la atribución a GGE de méritos que, consideraban, les pertenecían a otros oficiales, cuyos nombres y apellidos mencionaron (Castillo, Landriel, Herrera, Cáceres, Ibarra, entre otros). Estos ocho jefes milicianos acordaron con mirada crítica en que GGE había efectivamente participado en la Expedición del Fierro (sin concederle, empero, la sujeción de los cuatro caciques) y también en algunas corridas al Chaco, aunque siempre cerca de la reducción. Un par convalidaron la concurrencia de GGE a la entrada de Matorras, pero descontándole algunos puntos. Por ejemplo, el sargento mayor Juan Vicente Jaymes, que acreditaba más de treinta años de servicios "en guerra viva", sostuvo que, aunque GGE había partido "del río del Valle en compañía de un tal Acevedo y un indio del Payquín y que con la amistad de estos y experimentada baquía salió Espínola a Santa Fe", nada sabía del "curioso diario", "ni menos que se haya ofrecido tan voluntario" (Cuaderno 3, f. 23). ${ }^{36}$

Lo que todos los compañeros de armas de GGE negaron de plano fue el presunto "orden" reciente del camino de los Porongos. Desde mediados del siglo -o sea, a partir del traslado de la reducción a Sumampa- podía transitarse tranquilamente por allí, y para entonces GGE era demasiado joven. ${ }^{37}$ Tampoco era cierta, decían, su

\footnotetext{
${ }^{34}$ Eran conservadores los funcionarios instituidos para la conservación de ciertos derechos, privilegios o bienes, ya pertenecieran al ámbito secular como al eclesiástico. Entendemos que en la reducción se trataba de una figura de supervisión.

${ }^{35}$ La cursiva es nuestra.

${ }^{36}$ El fuerte San Fernando del Río del Valle reemplazó al de Rosario y fue el punto de partida y de llegada de la expedición de Matorras de 1774.

${ }^{37}$ Según hemos podido constatar a partir de los registros parroquiales de Sumampa, los grandes malones de mocovíes que afligieron la frontera de Chupilta pueden fecharse entre 1737 y 1738, entre 1745 y 1748 y en 1751. En esos años, los párrocos anotaron las defunciones de los feligreses "que mataron los indios", anotaciones que no se repiten posteriormente y vuelven verosímiles los dichos de los testigos.
} 
intervención durante la visita de Matorras, ni la conducción de tropas al Alto Perú (las había entregado en Oratorio para regresarse a su casa), ni la perversidad de los "enemigos capitales" de la primera sumaria. Antes bien, aquellos hombres fueron calificados de "españoles nobles, honrados y enacendados", "sujetos de buenos procedimientos", que habían obtenido "empleos honoríficos así en lo político como en lo militar" (Cuaderno 3, f. 20).

En un estudio reciente, María Luján Rosas (2019) bosquejó un retrato muy ajustado de los oficiales milicianos de la frontera tucumano-chaqueña para un período anterior al que analizamos: fines del siglo XVII e inicios del XVIII. Rosas ha llamado la atención sobre el papel articulador de estos sujetos, sobre sus funciones en la financiación de entradas y de fuertes y sus capacidades de liderazgo. Aunque más tardío, el perfil de GGE entra muy bien en el descripto por Rosas. También él era un personaje local que conocía de primera mano los dispositivos fronterizos ( $y$, si le creemos a García de Villar, que contribuía a solventarlos) y tenía contactos con gente "del otro lado". ${ }^{38}$ ¿Sería su experiencia con los abipones reducidos la que le habilitara la relación con su guía en la expedición de 1774, aquel mocoví "del Payquín"? No es inverosímil. Por desgracia, este expediente tan generoso en otro tipo de informaciones las entrega a cuenta gotas cuando se trata de la relación entre GGE y los indígenas del Chaco, que presumimos fluida. Las estadías de nuestro hombre en la reducción, su cargo de juez conservador y la mentada (¿quizás heredada?) baquía darían a pensar en lazos estrechos que, sin embargo, parecían no prolongarse en su lugar de residencia habitual. Como si las "pandillas" armadas de Ambargasta -sus "mulatos y agregados" y parientes; la compañía de Gabriel Espínola- estuvieran desconectadas respecto de las de los indios de la frontera.

Por cierto, hemos visto que los años de Espínola eran diferentes -quizás menos convulsionados- de los que estudia Rosas. Ya se dijo que Sumampa solo había conocido pocos y ya olvidados repartos de encomienda, y las informaciones de carácter local permiten suponer que, por lo menos en este sector de la frontera, dominaba en los años 80 una relativa tranquilidad (no así a orillas del río Salado, al menos siguiendo las actas capitulares). Quizás, incluso mientras se desmoronaba por falta de atención y recursos, la presencia de la reducción ayudaba a morigerar algunos conflictos fronterizos: ya vimos que Espínola fue acusado de todo tipo de delitos, pero nadie mencionó a los indígenas, reducidos o no, como parte de su plebeya clientela. Tampoco surgen en el juicio sirvientes abipones o mocovíes que nos hagan pensar en capturas de "piezas": GGE tenía esclavos y agregados a los que se percibía como mulatos, no como indios.

Una nueva sumaria iniciada contra GGE y sus hijos por un alcalde de Santa Hermandad en 1796 arroja alguna nueva luz sobre este asunto. Doce años después del proceso, cuatro connotados vecinos de Ambargasta volvieron a denunciar por abigeato al clan Espínola. Esta vez, el sargento mayor y juez comisionado Josep de Acuña (ya sindicado como víctima y testigo en el proceso anterior) añadió nuevas y significativas precisiones:

\footnotetext{
${ }^{38}$ En el mismo sentido, la sustracción de armas y de unas "cadenas del Rey", de la reducción hablaría de cierta "privatización", o mejor, de confusión entre los recursos reales y privados, ligada al mantenimiento de los dispositivos de defensa. Véase Judith Farberman (2021).
} 
El dho Guillermo, por interpretación que tiene con los abipones de la reducción, a quienes suele regalar por algunos días en su casa cuando le vienen a verlo, llegó una vez cerca de la casa del declarante y de sobre una loma les mostró su casa y les dijo que el declarante tenía mucha plata, incitándoles a la codicia con alguna depravada intención lo cual declaró y dio a entender al declarante una india mocoví que tiene en su casa. ${ }^{39}$

De la cita, nos quedamos con nuestro GGE agasajando a los abipones en La Horqueta, como quizás acostumbraba a hacerlo en la reducción. En todo caso, si GGE también tenía predicamento entre los abipones, si los hacía llegarse hasta Ambargasta para convidarlos con el ganado propio o ajeno, su figura podía volverse más inquietante todavía para sus enemigos. ${ }^{40}$ ¿Era esta base de poder, más la compañía miliciana de su hijo, más sus agregados personales, la que profundizaba los conflictos con sus vecinos más poderosos? ¿O acaso ese variopinto grupo era cuanto le quedaba en un nuevo contexto de fortalecimiento de los agentes judiciales?

Como fuera, nuestro hombre y su hijo pasaron más de dos años en una cárcel común, a pesar de los reclamos del defensor que denunciaba amargamente su desafuero y las condiciones de la prisión (muy especialmente, el tener que compartirla con negros y mulatos). ${ }^{41}$ También las dilaciones en la soltura fueron objeto de reiterados reclamos hasta que el mismo marqués de Sobremonte decidió la liberación de los prisioneros.

\section{Epílogo}

La sentencia del gobernador intendente terminó por beneficiar a los reos con la absolución, la restitución de los bienes embargados y la condonación de la fianza (vista la "dilatada prisión"). Mientras los Espínola fueron condenados a asumir las costas del proceso, Pillo Macana fue eximido por su "notoria pobreza". Por último, en prevención del "aumento de los disturbios" que causaría el regreso del trío a Ambargasta, se dispuso su alejamiento por dos años a una distancia de cuarenta leguas. La larga temporada en la cárcel afectó la economía de GGE -quien solicitó permiso para vender a uno de sus esclavitos con el objeto de mantener su casa- pero más todavía vulneró su honor: ya comprobamos que, doce años después del proceso, los Espínola serían nuevamente acusados de ladrones por los mismos vecinos. ${ }^{42}$

Entendemos que la trayectoria de GGE, aun cuando varias incógnitas permanezcan sin despejar, refleja ajustadamente el doble mundo del que provenía y que la última sumaria de 1796 permitiría conectar. Más que la propiedad de tierras como vimos, un patrimonio familiar gestionado en común y amasado por el capitán

\footnotetext{
${ }^{39}$ Gerez Calderón, Domingo. Sobre sumaria información, 1796. Tribunales, Legajo 13, Expediente 35.

${ }^{40}$ En este expediente, los robos de ganado parecen haber tenido como objetivo el consumo directo y no las ventas, como en el proceso de 1784 .

${ }^{41}$ El defensor solicitó que padre e hijo fueran trasladados al cuartel de la tropa o a "uno de los cuartos altos del cabildo", de modo de tener "cárcel correspondiente a las calidades de sus personas". Aunque Sobremonte accedió en un primer momento, el traslado no llegó a efectuarse por rumores acerca de los planes de fuga de GGE (Cuaderno 2, folio 83).

${ }^{42}$ En 1788, GGE pedía vista de los autos con el objeto de que el alcalde ordinario Domingo Santillán "y los falsos delatores sus parientes" se hicieran cargo de los gastos del proceso. "No puedo soportar la suma inopia en que me ha dejado el presente litigio y más de dos años en injusta carcelería" (Cuaderno 3, folio 79).
} 
Espínola en la generación anterior-, la fuente del poder de GGE residía en su liderazgo sobre parientes, agregados y tropas milicianas, socios desiguales en el goce del producto de las actividades lícitas e ilícitas del clan. Pero también había más que eso: de los Espínola se temían los "tumultos" que pudieran acaudillar. Como pudimos comprobar, los incidentes narrados en la sumaria remitían todos a la peligrosa tendencia de GGE de no reconocer a las justicias capitulares para ejercer la propia, amparándose en su grado militar y desoír las novedades reformistas. Quizás, también sobre estos desafíos se edificaba la popularidad de nuestro hombre, desafíos que ya no podían tener lugar en el nuevo contexto. Según relató don Antonio García Villegas, cuando GGE era todavía un joven alférez había prendido a un soldado por matar a un transeúnte y:

con solo un par de grillos, lo custodió (GGE) en la pampa del Oratorio de esta jurisdicción en un toldo qe fue la cárcel; todo lo que necesitó para seguirle la causa y finalizó al delincuente alcabucéandolo a lo militar, por no haber otra forma en aquel paraje. (Cuaderno 3, f. 9)

¿Habría aprendido GGE a "ser caudillo" en Concepción de Abipones, tan cerca de la pampa del Oratorio? En todo caso, como dejan ver las sumarias, su autoridad era más respetada que la de otros, aunque tuvieran mayor jerarquía o competencias más específicas.

No es que estas formas de ejercicio de la autoridad fueran excepcionales en las fronteras, incluida la de Chupilta. ${ }^{43}$ Un expediente algo más tardío iniciado contra los hermanos Leguizamo -los "bandidos" mencionados por un testigo como cómplices ocasionales de GGE- expone cuestiones muy similares a las que hemos revisado en este artículo. ${ }^{44}$ Silverio y Pablo, perseguidos por salteadores y traficantes de ganado, vivían al abrigo de ciertos estancieros de Sumampa cuya honradez -como la de GGEse hallaba en tela de juicio. Y sin embargo, varios testigos, aun cuando reconocían la ocupación ilegal de los reos, entendieron que la prisión que el juez comisionado y teniente de milicias Carlos Vivas había hecho de Pablo Leguizamo era producto del abuso de autoridad. Así lo adujo Silverio Leguizamo mientras liberaba a su hermano de las prisiones: "porque no lo conocía por juez, hizo dicha resistencia". Más aún: desde la perspectiva de Silverio, la injusticia y el abuso de autoridad estaban en el origen de su carrera de salteador ("dio en salteador a causa de perseguirlos Carlos Vivas").

Nunca sabremos si de verdad los hermanos Leguizamo formaban parte de la clientela de GGE, aunque no es imposible. En todo caso, se ajustaban bien al perfil de los seguidores de nuestro fascinante personaje.

\section{Referencias bibliográficas}

1. Alessandroni G. y Rustán, M. (2001). La aplicación de la justicia en la campaña. Córdoba, 1785- 1790. Cuadernos de Historia. Serie Economía y Sociedad, 4, 11-

\footnotetext{
43 Ver Florencia Roulet (2002); María Rustán (2011). La primera referencia es un artículo sobre el comandante José Francisco de Amigorena, sin duda una figura de mayor envergadura que GGE, pero cuyas prácticas y conflictos nos recuerdan las de nuestro protagonista.

${ }^{44}$ Leguizamo Pablo, sobre calumnias e injurias, 1793. Tribunales, Legajo 9, Expediente 73, folio 38.
} 
Farberman, J. Las tribulaciones del sargento mayor. Conflictos de jurisdicción y relaciones fronterizas en el sur de Santiago del Estero, a fines del siglo XVIII

37.

https://revistas.unc.edu.ar/index.php/cuadernosdehistoriaeys/article/view/9878

2. Archivo Histórico de Santiago del Estero (2013). Actas Capitulares de Santiago del Estero. Tomo III, años 1767-1777.

3. Barriera, D. (2018). Del gobierno de los jueces a la desjudicialización del gobierno. Desenredos en la trenza de la cultura jurisdiccional en el Río de la Plata. Santa Fe, 1780- 1860. En A. Agüero, A. Slemian y R. Fernández de Sotelo (Coords.) Jurisdicciones, Soberanías, Administraciones: Configuración de los espacios políticos en la construcción de los estados nacionales en Iberoamérica (pp. 371-406). Editorial de la Universidad Nacional de Córdoba/El Colegio de México.

4. Bravo y Taboada, L. (1944). La Consolación de Sumampa. Páginas histórico religiosas sobre la imagen compañera de la Virgen de Luján. Gráfica San Pablo.

5. Cutrera, M. L. (2019). "Pensar la paz". Sobre las negociaciones entre algunos gobernadores del Tucumán y varios caciques del Chaco en la década de 1770. Fronteras de la Historia, 24 (1), 100-131. https://doi.org/10.22380/20274688.527

6. Dainotto, E. (2012). Política y poder en Córdoba borbónica. Instituciones, espacios y prácticas. 1783-1797. Ferreyra Editor.

7. Farberman, J. (2019, 2 de octubre). Indivisión, conflicto y derechos de propiedad en Los Llanos de La Rioja y en Sumampa (Santiago del Estero), siglos XVIII y XIX. Una perspectiva comparada [ponencia]. III Congreso Internacional de la Asociación Latinoamericana e Ibérica de Historia Social. Lima, Perú.

8. Farberman, J. (2021). Población, tierras y sociedad de frontera en Sumampa (sur de Santiago del Estero), a fines del siglo XVIII. Población y Sociedad (en prensa).

9. Farberman, J. y Ratto, S. (2014). Actores, políticas e instituciones en dos espacios fronterizos chaqueños: la frontera santiagueña y el litoral rioplatense entre 1630-1800. Prohistoria, historia, políticas de la historia 22, 3-31. https://dialnet.unirioja.es/servlet/articulo?codigo $=5843080$

10. Fradkin, R. (2009). Tradiciones militares coloniales. El Río de la Plata antes de la revolución. En F. Heinz (Comp.) Experiências nacionais, temas transversais: subsídios para uma história comparada da América Latina (pp. 74-126). Oikos.

11. Garavaglia, J. C. (1984). La guerra en Tucumán colonial: sociedad y economía en un área de frontera (1660-1760). HISLA, IV, 21-34.

12. Gramajo, A. y Martínez Moreno, H. (2005). Sumampa y Ojo de Agua en las sierras del Sur. Quinto Centenario. 
Farberman, J. Las tribulaciones del sargento mayor. Conflictos de jurisdicción y relaciones fronterizas en el sur de Santiago del Estero, a fines del siglo XVIII

13. Ledesma, R. (1957). Sumampa. Relación histórico arqueológica. Universidad Nacional de Tucumán.

14. Lucaioli, C. (2011). Abipones en las fronteras del Chaco. Una etnografía histórica sobre el siglo XVIII. Sociedad Argentina de Antropología.

15. Lucaioli, C. (2014). Negociación y diplomacia en las fronteras del Chaco. Nuestra Señora de la Concepción de Abipones. Revista Historia e Cultura, 3 (2), 380-405. https://doi.org/10.18223/hiscult.v3i2.1362

16. Nesis, F. (2008). El camino de Paikín: un acercamiento a los grupos mocoví del Chaco a través del tratado de 1774. Avá, 13, s/p. http://www.ava.unam.edu.ar/images/13/pdf/ava13_05_nesis.pdf

17. Polimene, M. P. (2011). El alcalde de la Hermandad del pago de Bajada entre 1784 y 1786. En M. P. Polimene (Coord.) Autoridades y prácticas judiciales en el Antiguo Régimen: problemas jurisdiccionales en el Río de la Plata, Córdoba, Tucumán, Cuyo y Chile (pp. 77-92). Prohistoria.

18. Punta, A. (2001). Córdoba y la construcción de sus fronteras en el siglo XVIII. Cuadernos de Historia. Serie Economía y Sociedad, 4, 159-194.

19. Punta, A. (2003). Legislación y mecanismos formales de aplicación de la justicia en Córdoba del Tucumán durante la primera gobernación intendencia, 1783, 1797. Claroscuro, 3, 207-237.

20. Rosas, M. L. (2019). Guerra y movilización en el Tucumán colonial. Conflictos, tensiones y convivencia en la frontera con el Chaco a fines del siglo XVII. Universidad Nacional de Luján (en prensa).

21. Roulet, F. (2002). Guerra y diplomacia en la frontera de Mendoza. La política indígena del comandante José Francisco de Amigorena (1779-1799). En L. Nacuzzi (Comp.) Funcionarios, diplomáticos, guerreros. Miradas hacia el otro en las fronteras de Pampa y Patagonia, siglos XVIII y XIX (pp. 65-117). Sociedad Argentina de Antropología.

22. Rustán, M. (2011). Jurisdicciones en cuestión. Cabildos y autoridades militares en la administración borbónica. Gobernación Intendencia de Córdoba a finales del siglo XVIII. En M. P. Polimene (Coord.) Autoridades y prácticas judiciales en el Antiguo Régimen: problemas jurisdiccionales en el Río de la Plata, Córdoba, Tucumán, Cuyo y Chile (pp. 139-156). Prohistoria.

23. Sellés-Martínez, J. (2020). El registro del Mesón de Fierro en la cartografía de los siglos XVI a XIX. Revista de la Facultad de Ciencias Exactas, Físicas y Naturales, 7(1), 213-222. https://revistas.unc.edu.ar/index.php/FCEFyN/article/view/28665 
24. Siegrist, N. (2011). Un original Censo de Santiago del Estero en los Registros Parroquiales de la Iglesia de Sumampa: 1698-1794. Revista del Instituto de Ciencias Genealógicas, 34, 579-685.

25. Sosnowski, D. (2020). La frontera oriental de Córdoba. Expansión colonial, relaciones interétnicas y dispositivos de control en un espacio de interacción $\begin{array}{lllll}\text { (siglo } \quad \mathrm{XVIII} \text { ). } & \text { Tefros, } & 18 & \text { (1), } & \text { 75-109. }\end{array}$ http://www2.hum.unrc.edu.ar/ojs/index.php/tefros/article/view/800

26. Tío Vallejo, G. (1998). La "buena administración de justicia" y la autonomía del cabildo. Tucumán, 1770-1820. Boletín del Instituto Ravignani, 18, 35-81.

27. Togo, J., Garay L. y Bonetti, C. (2008). La reducción de abipones. Un análisis de las políticas de colonización. Indoamérica, 2 (2), 93-114.

28. Togo, J., Garay, L. y Bonetti, C. (2009). Padrones de los pueblos de indios de Santiago del Estero durante el siglo XVIII, 1701-1786. Universidad Nacional de Santiago del Estero.

29. Zamora, R. (2011). "...que por su juicio y dictamen no puede perjudicar a la quietud Publica...". Acerca de la administración de la justicia en San Miguel de Tucumán a fines del siglo XVIII. En M. P. Polimene (Coord.) Autoridades y prácticas judiciales en el Antiguo Régimen: problemas jurisdiccionales en el Río de la Plata, Córdoba, Tucumán, Cuyo y Chile (pp. 115-138). Prohistoria. 